\title{
Nanoheterostructure Cation Exchange: Anionic Framework Conservation
}

\author{
Prashant K. Jain, ${ }^{1,2,3, \dagger}$ Lilac Amirav, ${ }^{1,3, \dagger}$ Shaul Aloni, ${ }^{4}$ A. Paul Alivisatos ${ }^{1,3, *}$ \\ ${ }^{I}$ Department of Chemistry, University of California, Berkeley CA 94720 \\ ${ }^{2}$ Miller Institute for Basic Research in Science, University of California, Berkeley, CA 94720 \\ ${ }^{3}$ Materials Research Division, Lawrence Berkeley National Lab, Berkeley, CA 94720 \\ ${ }^{4}$ Molecular Foundry, Lawrence Berkeley National Lab, Berkeley, CA 94720
}

RECEIVED DATE (automatically inserted by publisher); E-mail: alivis@berkeley.edu

In ionic nanocrystals, especially transition metal chalcogenides, the cationic sub-lattice can be replaced with a different metal ion via a fast, simple, and reversible place-exchange, altering the composition of the nanocrystal, while preserving its size and shape.$^{1-7}$ It is generally assumed that during such an exchange, the anionic framework of the crystal is conserved, while the cations, due to their relatively smaller size and higher mobility, undergo replacement. This has not, however, been experimentally proven or utilized, as only single-phase nanocrystals have so far been transformed using cation exchange. Preservation of the anionic framework during cation exchange would enable transformation of multi-component nanoheterostructures, while conserving not only the nanostructure size and shape, but also the compositional interface between the constituents. This would greatly extend the domain of cation exchange to the design of ever more complex nanostructures. In this Communication, we demonstrate that, indeed, the anionic framework is preserved during cation exchange, and that this can be utilized for accessing customized nanoheterostructures.

The model heterostructure selected is a seeded rod consisting of a spherical CdSe nanocrystal embedded in a CdS nanorod. ${ }^{8-10} \mathrm{~A}$ unique functional feature of such a structural arrangement is the ability to design the relative band alignment of the two semiconductors across the interface, allowing independent tuning of the spatial distribution of electrons and holes along the elongated dimension. ${ }^{11-16}$ The seeded rod is a canonical example of a nanoheterostructure that allows customization of electronic properties for applications such as force sensing, ${ }^{17}$ photocatalysis, ${ }^{18}$ optoelectronics, ${ }^{19-21}$ and quantum information technology. ${ }^{22}$

A 40-nm long $\mathrm{CdSe} / \mathrm{CdS}$ seeded nanorod synthesized with a 3.9-nm seed (Supporting Information) exhibits absorption features (Fig. 1A) attributable to excitons in the CdSe seed (600 nm and $562 \mathrm{~nm})$ and the CdS rod $(460 \mathrm{~nm})$ and strong photoluminescence (PL) due to exciton recombination in the seed (Fig. 1B). Complete cation exchange of the nanorods with $\mathrm{Cu}^{+}$results in the loss of $\mathrm{CdS}$ and $\mathrm{CdSe}$ excitonic features and the emergence of an absorption band-edge around $850 \mathrm{~nm}$, typical of $\mathrm{Cu}$ chalcogenides (indirect bulk band gap $\sim 1.2 \mathrm{eV}$ ). Back-conversion of the $\mathrm{Cu}_{2} \mathrm{Se} / \mathrm{Cu}_{2} \mathrm{~S}$ seeded rod to $\mathrm{Cd}^{2+}$ recovers all excitonic features of the original structure (Fig 1A, B, and D).

The PL peak maximum, due to the confined nature of the emitting exciton in the seed, is known to be highly sensitive to the seed diameter (Fig. 1C). It is noteworthy that following two cycles of exchange, the PL peak recovered with a similar position as that of the initial nanorods. This indicates complete conservation of the selenide seed embedded in the sulfide rod

†equal contribution

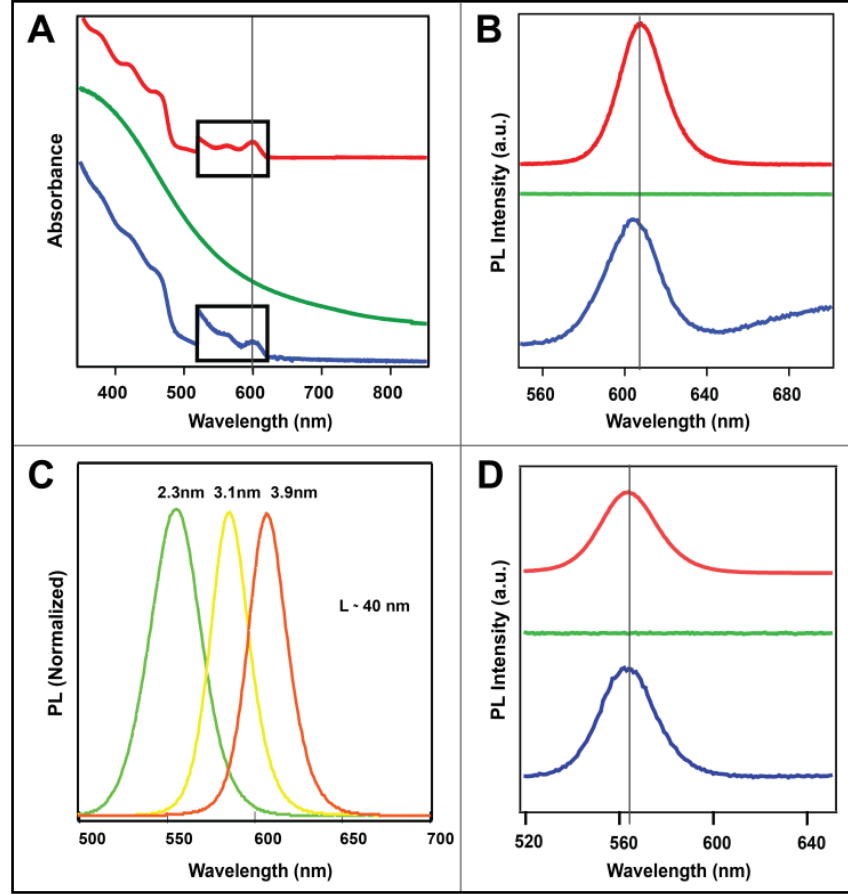

Figure 1. A) Absorbance and B) photoluminescence (PL) spectrum of a 40-nm long CdS nanorod with an embedded 3.9-nm CdSe nanocrystal (top), following complete exchange with $\mathrm{Cu}^{+}$(middle), and back-exchange to $\mathrm{Cd}^{2+}$ (bottom). C) Sensitivity of the PL peak position to the CdSe seed diameter D) PL spectrum of a seeded nanorod with a $2.3-\mathrm{nm} \mathrm{CdSe}$ nanocrystal embedded in a 40-nm long CdS rod (top), following $\mathrm{Cu}^{+}$ exchange (middle), and back-exchange to $\mathrm{Cd}^{2+}$ (bottom), showing recovery of the peak to the same position (within $0.5 \mathrm{~nm})$ and fwhm $(\sim 17$ $\mathrm{nm}$ ) as the original nanorods

throughout the forward and reverse transformations. Remarkably, this holds for a seed diameter as small as $2.3 \mathrm{~nm}$ (Fig. 1D). For the 3.9-nm seed, the PL maximum position recovers to within 4 $\mathrm{nm}$, indicating no more than $4 \%$ size change (based on the trend in Fig. 1C). However, a significant part of this shift may in fact be attributed to effects unrelated to a size change. For instance, backexchange of the $\mathrm{Cu}_{2} \mathrm{Se} / \mathrm{Cu}_{2} \mathrm{~S}$ structure could result in a strained $\mathrm{CdSe} / \mathrm{CdS}$ interface, especially in the case of the larger seed, leading to a blue-shift in the recovered PL. ${ }^{17,23}$ In addition, the 3.9-nm seed is exposed to the surface/ligand environment, making it sensitive to dielectric changes in the ligand shell and increase in surface traps resulting from the cation exchange process, ${ }^{1}$ possibly 


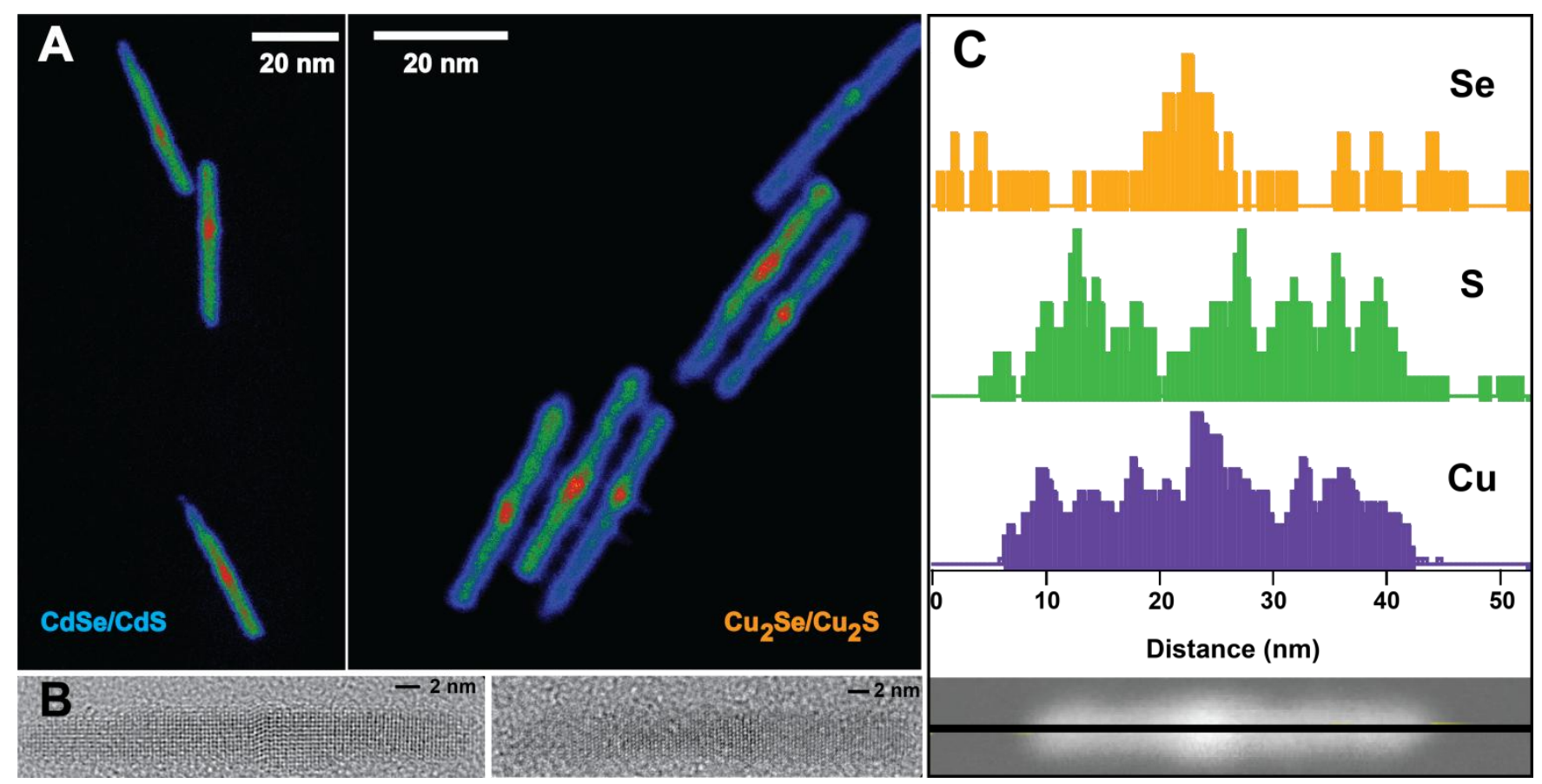

Figure 2. A) High-angle annular dark-field image rendered as a pseudo-color map and B) high-resolution transmission electron micrograph of $\mathrm{CdSe} / \mathrm{CdS}$ (left) and $\mathrm{Cu}_{2} \mathrm{Se} / \mathrm{Cu}_{2} \mathrm{~S}$ (right) seeded rods. C) Energy dispersive X-ray line-scan across a representative $\mathrm{Cu}_{2} \mathrm{Se} / \mathrm{Cu}_{2} \mathrm{~S}$ nanorod. The position of the selenide seed in the EDS line-scan agrees with the location of high Z-contrast in the HAADF image shown at the bottom. Line profiles of absolute intensity through the nanorods in A) are shown in the Supporting Information.

causing the shift and the broad trap emission at longer wavelengths in the recovered PL (Fig. 1B). The 2.3-nm seed, in which case sensitivity of its PL position to the external surface/ligand environment is expected to be minimal due to complete embedment in the rod, shows recovery of its PL maximum position to within $0.5 \mathrm{~nm}$, implying insignificant size change. This demonstrates that the anionic framework is preserved during the exchange without significant mixing of the anions across the interface, allowing the original heterostructure morphology to be conserved.

High-angle annular dark-field (HAADF) and high resolution transmission electron microscopy (HRTEM) of the $\mathrm{Cd}$ and $\mathrm{Cu}$ seeded rods (Fig. 2, Supporting Information) show that they maintain their size and shape during exchange. In HAADF images (Fig. 2A), the selenide seed exhibits higher Z-contrast compared to the sulfide rod, allowing visualization of seed location. This is further supported by elemental dispersive X-ray (EDX) line scans across a representative rod (Fig. 2C). This confirms that the position of the seed within the rod is conserved during the ionic transformation.

Anionic framework conservation allows access to new and unique heterostructures, otherwise difficult to make via colloidal synthesis. For example, a structure with a PbSe nanocrystal embedded in a $\mathrm{PbS}$ rod has not yet been described in the literature. Such a structure would enable band-gap engineering and tuning of electron/hole transport properties in the nearinfrared (NIR) region, potentially useful for NIR photovoltaics, photodetectors, ${ }^{24}$ and fluorescent imaging labels.

To demonstrate this example, we started with $\mathrm{CdSe} / \mathrm{CdS}$ rods as templates and transformed them to a $\mathrm{PbSe} / \mathrm{PbS}$ structure by two successive cation exchange steps: $\mathrm{Cd}^{2+} \rightarrow \mathrm{Cu}^{+} \rightarrow \mathrm{Pb}^{2+}$ (Fig. 3A). Here, we extend a procedure developed by Luther et al. ${ }^{5}$ where ligands are employed to create a disparity between the solvation of divalent $\left(\mathrm{Cd}^{2+}\right.$ and $\left.\mathrm{Pb}^{2+}\right)$ and monovalent cations $\left(\mathrm{Cu}^{+}\right)$.
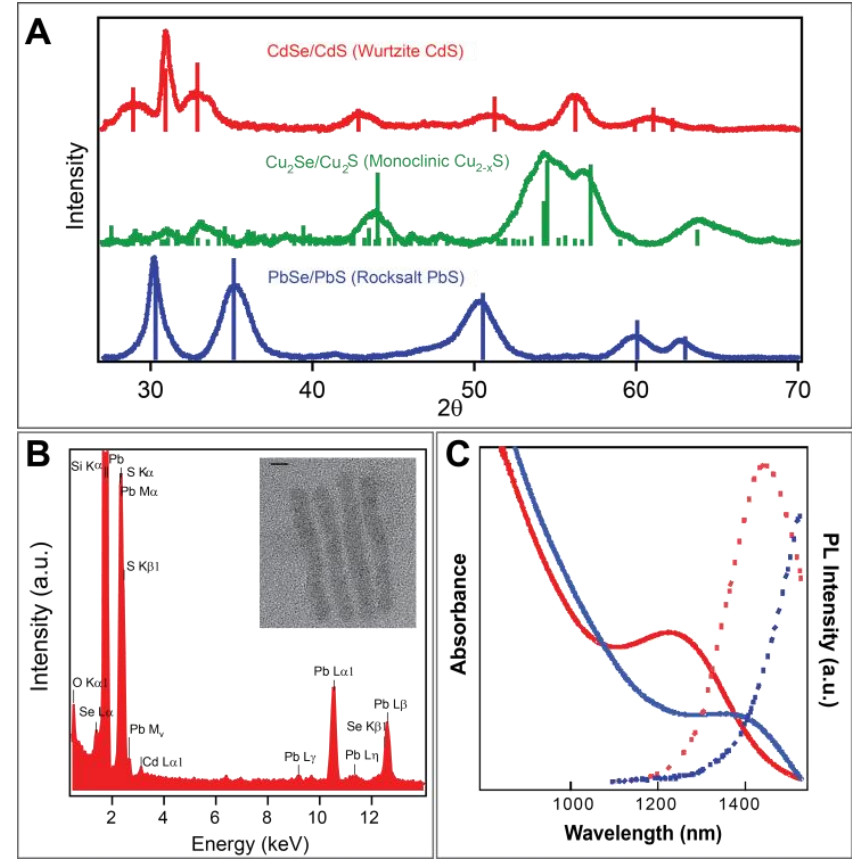

Figure 3. A) X-ray diffraction pattern showing exchange of CdSe/CdS (top) to $\mathrm{PbSe} / \mathrm{PbS}$ seeded rod with rock-salt structure (bottom) via $\mathrm{Cu}_{2} \mathrm{Se} / \mathrm{Cu}_{2} \mathrm{~S}$ with monoclinic crystal structure (middle). B) Energy dispersive X-ray spectra and (inset) transmission electron micrograph of $\mathrm{PbSe} / \mathrm{PbS}$ nanorods; scale bar: $5 \mathrm{~nm} \mathrm{C}$ ) Absorbance (solid) and photoluminescence spectra (dotted) of rods with a 3.9-nm (blue) and 2.3-nm (red) PbSe seed. Note that the PL detection sensitivity range is limited to $1550 \mathrm{~nm}$.

EDX spectra (Fig. 3B) and TEM (Fig. 3B inset) confirm the formation of $\mathrm{PbSe} / \mathrm{PbS}$ nanorods with size and shape preserved. The NIR spectrum (Fig. 3C) exhibited by these nanorods is 
characteristic of the excitonic absorption of the $\mathrm{PbSe}$ seed, ${ }^{25}$ coupled with contribution from the PbS nanorod. ${ }^{5}$ Consistently, a size-dependent excitonic absorption is seen for $\mathrm{PbSe} / \mathrm{PbS}$ rods with two different seed diameters $(3.9 \mathrm{~nm}$ and $2.3 \mathrm{~nm}$ ). The exciton absorption of the PbSe seed is red-shifted (by 0.1 and 0.25 $\mathrm{eV}$ for larger and smaller seed, respectively) from the expected value for the corresponding bare $\mathrm{PbSe},{ }^{25}$ consistent with embedment in a PbS matrix. ${ }^{21,26,27}$ The rods also show seed sizedependent NIR emission.

The phenomenon of anionic framework preservation in cation exchange can be generalized to achieve a wide gamut of design goals in nanoheterostructure synthesis. For instance, structures with multiple interfaces or complex topologies may be transformed with high ease and fidelity.

Acknowledgements: This work was supported by the Director, Office of Science, Office of Basics Energy Sciences, Materials Sciences and Engineering Division, of the U.S. Department of Energy under Contract No. DE-AC02-05CH11231. Electron microscopy and NIR PL measurements were performed at the LBNL Molecular Foundry supported by the Office of Science, Office of Basic Energy Sciences, of the U.S. Department of Energy under Contract No. DE-AC02-05CH11231. P.J. thanks the Miller Institute for the Miller Fellowship. We thank Jessy Baker and Charina Choi for discussions.

Supporting Information Available: Details of $\mathrm{CdSe} / \mathrm{CdS}$ rod synthesis with different seed diameters; cation exchange procedures; details of characterization (STEM, EDAX, XRD, optical spectra); seed position statistics for $\mathrm{Cd}$ and $\mathrm{Cu}$ seeded nanorods. This material is available free of charge via the internet at http://pubs.acs.org.

\section{References}

1. Son, D. H.; Hughes, S. M.; Yin, Y.; Paul Alivisatos, A. Science 2004, 306, 1009.

2. Chan, E. M.; Marcus, M. A.; Fakra, S.; EINaggar, M.; Mathies, R. A.; Alivisatos, A. P. J. Phys. Chem. A 2007, 111, 12210

3. Robinson, R. D.; Sadtler, B.; Demchenko, D. O.; Erdonmez, C. K.; Wang, L.; Alivisatos, A. P. Science 2007, 317, 355.

4. Sadtler, B.; Demchenko, D. O.; Zheng, H.; Hughes, S. M.; Merkle, M. G.; Dahmen, U.; Wang, L.; Alivisatos, A. P. J. Am. Chem. Soc. 2009, 131 5285 .

5. Luther, J. M.; Zheng, H.; Sadtler, B.; Alivisatos, A. P. J. Am. Chem. Soc. 2009, 131, 16851.

6. Pietryga, J. M.; Werder, D. J.; Williams, D. J.; Casson, J. L.; Schaller, R D.; Klimov, V. I.; Hollingsworth, J. A. J. Am. Chem. Soc. 2008, 130 4879 .

7. Wark, S. E.; Hsia, C.; Son, D. H. J. Am. Chem. Soc. 2008, 130, 9550.

8. Talapin, D. V.; Koeppe, R.; Götzinger, S.; Kornowski, A.; Lupton, J. M.; Rogach, A. L.; Benson, O.; Feldmann, J.; Weller, H. Nano Lett. 2003, 3 , 1677 .

9. Carbone, L., et al Nano Lett. 2007, 7, 2942.

10. Talapin, D. V.; Nelson, J. H.; Shevchenko, E. V.; Aloni, S.; Sadtler, B.; Alivisatos, A. P. Nano Lett. 2007, 7, 2951.

11. Lupo, M. G.; Della Sala, F.; Carbone, L.; Zavelani-Rossi, M.; Fiore, A.; Lüer, L.; Polli, D.; Cingolani, R.; Manna, L.; Lanzani, G. Nano Lett 2008, 8,4582 .

12. Steiner, D.; Dorfs, D.; Banin, U.; Della Sala, F.; Manna, L.; Millo, O. Nano Lett. 2008, 8, 2954.

13. Sitt, A.; Sala, F. D.; Menagen, G.; Banin, U. Nano Lett. 2009, 9, 3470.

14. Gómez, D. E.; van Embden, J.; Mulvaney, P.; Fernée, M. J.; RubinszteinDunlop, H. ACS Nano 2009, 3, 2281.

15. Müller, J.; Lupton, J. M.; Rogach, A. L.; Feldmann, J.; Talapin, D. V.; Weller, H. Phys. Rev. B 2005, 72, 205339.

16. Müller, J.; Lupton, J. M.; Lagoudakis, P. G.; Schindler, F.; Koeppe, R.; Rogach, A. L.; Feldmann, J.; Talapin, D. V.; Weller, H. Nano Lett 2005 5,2044 .

17. Choi, C. L.; Koski, K. J.; Sivasankar, S.; Alivisatos, A. P. Nano Lett. $2009,9,3544$.

18. Amirav, L.; Alivisatos, A. P. J. Phys. Chem. Lett. 2010, 1, 1051

19. Kraus, R. M.; Lagoudakis, P. G.; Rogach, A. L.; Talapin, D. V.; Weller, H.; Lupton, J. M.; Feldmann, J. Phys. Rev. Lett. 2007, $98,017401$.

20. Deka, S.; Falqui, A.; Bertoni, G.; Sangregorio, C.; Poneti, G.; Morello, G.; Giorgi, M. D.; Giannini, C.; Cingolani, R.; Manna, L.; Cozzoli, P. D. J. Am. Chem. Soc. 2009, 131, 12817.
21. Lifshitz, E.; Brumer, M.; Kigel, A.; Sashchiuk, A.; Bashouti, M.; Sirota M.; Galun, E.; Burshtein, Z.; Le Quang, A. Q.; Ledoux-Rak, I.; Zyss, J. J. Phys. Chem. B 2006, 110, 25356.

22. Pisanello, F.; Martiradonna, L.; Leménager, G.; Spinicelli, P.; Fiore, A.; Manna, L.; Hermier, J.; Cingolani, R.; Giacobino, E.; De Vittorio, M. Bramati, A. Appl. Phys. Lett. 2010, 96, 033101.

23. Smith, A. M.; Mohs, A. M.; Nie, S. Nat. Nano 2009, 4, 56.

24. McDonald, S. A.; Konstantatos, G.; Zhang, S.; Cyr, P. W.; Klem, E. J. D.; Levina, L.; Sargent, E. H. Nat. Mater. 2005, 4, 138.

25. Lifshitz, E.; Sashchiuk, A.; Kigel, A.; Brumer, M.; Bashouti, M.; Amirav L. In PbSe Nanocrystals: From Spherical Core-Shell Structures to Rods, Wires, Tetrapods, and Assemblies; Balandin, A. A., Wang, K. L., Eds.; Handbook of Semiconductor Nanostructures and Nanodevices; 2006; Vol. 2, pp 241-265.

26. Brumer, M.; Kigel, A.; Amirav, L.; Sashchiuk, A.; Solomesch, O.; Tessler, N.; Lifshitz, E. Adv. Funct. Mater. 2005, 15, 1111.

27. Bartnik, A. C.; Wise, F. W.; Kigel, A.; Lifshitz, E. Phys. Rev. B 2007, 75 245424. 
DISCLAIMER: This document was prepared as an account of work sponsored by the United States Government. While this document is believed to contain correct information, neither the United States Government nor any agency thereof, nor The Regents of the University of California, nor any of their employees, makes any warranty, express or implied, or assumes any legal responsibility for the accuracy, completeness, or usefulness of any information, apparatus, product, or process disclosed, or represents that its use would not infringe privately owned rights. Reference herein to any specific commercial product, process, or service by its trade name, trademark, manufacturer, or otherwise, does not necessarily constitute or imply its endorsement, recommendation, or favoring by the United States Government or any agency thereof, or The Regents of the University of California. The views and opinions of authors expressed herein do not necessarily state or reflect those of the United States Government or any agency thereof or The Regents of the University of California. 